\title{
TLC of selected sesquiterpenoids of the Asteraceae family
}

\author{
Gerard Nowak*, Renata Dawid-Pać, Maria Urbańska, Joanna Nawrot \\ Department of Medicinal and Cosmetic Natural Products, Poznań University of Medical Sciences, Mazowiecka 33, 60-623 Poznań, Poland
}

\section{Abstract}

Visual chromatography has been employed for a preliminary identification of natural compound of a group of sesquiterpene lactones - Centaurea bella Trautv., C. crocodylium L., C. lusitanica Boiss. et Reuter, Helenium hoopesii A. Gray = Dugaldia hoopesii (A. Gray) Rydb., Stizolophus balsamita (Lam.) Cass., Zoegea baldschuanica C. Winkl., germacranes - Santolina pinnata Viv. subsp. neapolitana (Jord. et Fourr.) Guinea = S. neapolitana Jord. et Fourr. A dependence of the colour of the spots, induced by anisaldehyde reagent, on the presence of several substituents in the germacranolide ring - derivatives of partnenolide and salonitenolide - has been identified. The structures of the skeleton in the ring of sesquiterpene lactones in Helenium hoopesii can also be established by thin layer chromatography (TLC). The analysis of the chromatograms of extracts from dry and fresh Centaurea crocodylium herb has shown significant differences as for the chemical composition. Two sorts of germacranes of Santolina pinnata subsp. neapolitana display a characteristic colour of the spots.

Keywords: sesquiterpene lactones, Asteraceae, TLC, identification

\section{Introduction}

Among natural compounds in the species of family Asteraceae, sesquiterpenoids play an important role. They constitute a valuable chemotaxonomic material and might be also decisive for the medicinal value of the raw material, as in Chamomillae anthodium, Cnici benedicti herba, Arnicae anthodium, Millefolii herba, Chrysanthemi partheni herba, Cichorii radix et herba. A recent study has revealed antibacterial and cytotoxic activities of sesquiterpene lactones [1]. These compounds can be detected through visual chromatography and isolated by simple column chromatography, with silica gel as the adsorbent.

The possibility of identification of several substituents at guaianolides by TLC with concentrated sulphuric acid as the developer had been mentioned earlier $[2,3]$. Now, visual chromatography of compounds of four other types of sesquiterpenoids has been presented: germacranolides, germacranes, seco-pseudoguaianolides and pseudoguaianolides.

To develop the spots, the sole anisaldehyde reagent, which proved selective enough to rate the colours of the spots of the compounds in question, was used.

\footnotetext{
*Corresponding author. Email: gnowak@ump.edu.pl

This is an Open Access digital version of the article distributed under the terms of the Creative Commons Attribution 3.0 License (creativecommons.org/licenses/ by/3.0/), which permits redistribution, commercial and non-commercial, provided that the article is properly cited.
}

\section{Material and methods}

\section{Plant material}

The plant materials used for the studies employed aerial parts of Centaurea bella, C. crocodylium, C. lusitanica, Helenium hoopesii, Santolina pinnata subsp. neapolitana, Stizolophus balsamita, Zoegea baldschuanica, plants cultivated and identified in the garden of Department of Medicinal and Cosmetic Natural Products, University of Medical Sciences in Poznań (Poland), where their voucher specimens are deposited.

\section{Isolation and identification of compounds}

The herbs, collected right before blooming (about $450 \mathrm{~g}$ each) were extracted with methanol three times. The methanol extracts were inundated with distilled water $\left(\mathrm{ca} .600 \mathrm{~cm}^{3}\right)$, after the evaporation of the solvent. The water phase was extracted with chloroform. The chloroform extracts, in turn, having been dried with anhydrous sodium sulphate, were used for thin layer chromatography and isolation of compounds. Furthermore, some methanol/water/chloroform extracts were prepared from Centaurea crocodylium herb, which had been collected at the same time and from the same plot as the herbs designed to be dried.

The extracts were separated by column chromatography on silica gel (Merck art. 7733). The fractions were subjected to repeated column chromatography on silica gel (Merck art. 7729) and eluted by right mobile phases. The structures of the isolated compounds (Fig. 1) were identified on the basis of $1 \mathrm{H}$ NMR, IR and EI mass spectroscopy and by comparing the obtained data with those of the reference compounds or reported data [4-8]. 


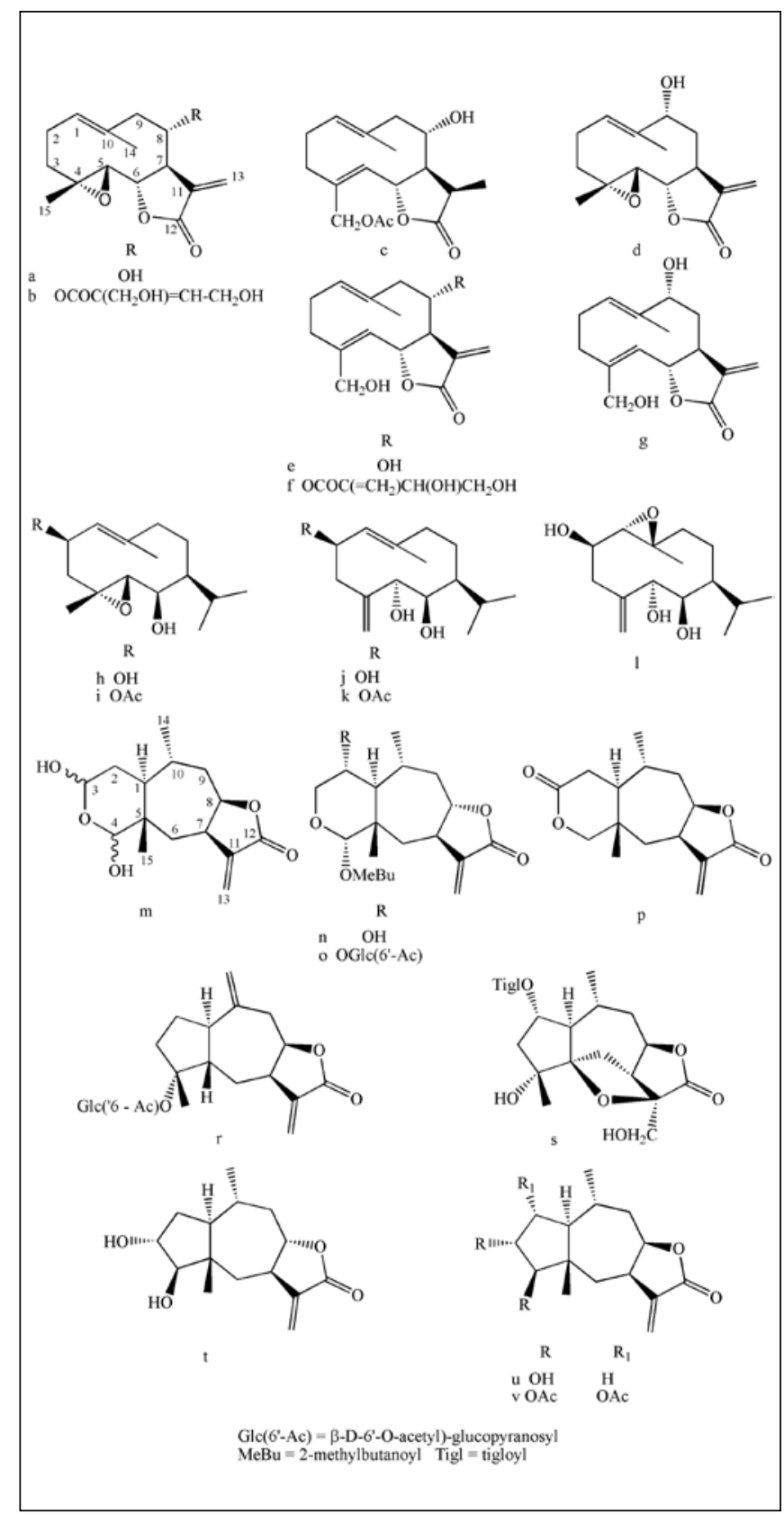

Fig. 1 Chemical structures of: a stizolin; b stizolicin; c cebellin M; d 9a-hydroxyparthenolide; e salonitenolide; $\mathbf{f}$ cnicin; $\mathbf{g}$ stenophyllolide; h $4 \beta, 5 \alpha$-epoxy-7 $\alpha \mathrm{H}$-germacr-1(10)E-ene-2 $\beta, 6 \alpha$-diol; i 2 -acetoxy, $4 \beta, 5 \alpha$-epoxy-7 $\alpha \mathrm{H}$-germacr-1(10)E-ene-6 $\beta$-ol; $\mathbf{j} 7 \alpha \mathrm{H}$-germacra-1(10) E,4(15)-diene-2 $\beta, 5 \alpha, 6 \beta$-triol; $\mathbf{k} 7 \alpha \mathrm{H}$-germacra-1(10)E,4(15)-diene-2acetoxy, $5 \alpha, 6 \beta$-diol; 1 1 $\alpha, 10 \beta$-epoxy-7 $\alpha \mathrm{H}$-germacr-4(15)ene-2 $\beta, 5 \alpha, 6 \beta$-triol; m hymenovin; $\mathbf{n}$ hymenoratin B; o hymenoratin B 2-O- $\beta$-D-(6'-O-acetyl)glucopyranoside; $\mathbf{p}$ floribundin; $\mathbf{r}$ lemmonin $\mathrm{A} ; \mathbf{s} 2 \alpha$-tigloyloxydugaldiolide; $\mathbf{t}$ neohymenoratin; $\mathbf{u}$ hymenoratin; $\mathbf{v}$ acetylhymenograndin.

\section{TLC analysis}

Thin-layer chromatrography was performed at room temperature on aluminium-backed silica gel plates DC Alufolien Kieselgel 60 (Merck art. 5553). 15-20 $\mu \mathrm{g}$ of each isolated compounds were applied per plate. Developed and dried chromatograms were sprayed by anisaldehyde reagent and heated at $100^{\circ} \mathrm{C}$ by 3 minutes. Spots of isolated compounds exhibited, mauve, violet, red-brown, black-blue, orange, yellow, cherryred and gray colours when examined 3-15 minutes from the time of spraying (Tab. 1).
Tab. 1 The colours of the spots of selected sesquiterpenoids isolated from Asteraceae family.

\begin{tabular}{|c|c|c|c|}
\hline No. & Compound & Plant & $\begin{array}{l}\text { Colour of } \\
\text { the spot in } \\
\text { anisaldehyde } \\
\text { reagent }\end{array}$ \\
\hline 1 & stizolin & Stizolophus balsamita & mauve \\
\hline 2 & stizolicin & & \\
\hline 3 & cebellin M & Centaurea bella & \\
\hline 4 & 9a-hydroxyparthenolide & Zoegea baldschuanica & violet \\
\hline 5 & salonitenolide & Centaurea crocodylium & red-brown \\
\hline 6 & cnicin & & \\
\hline 7 & stenophyllolide & Centaurea lusitanica & black-blue \\
\hline 8 & $\begin{array}{c}4 \beta, 5 \alpha \text {-epoxy- } 7 \alpha H \text {-germacr- } \\
1(10) E \text {-ene- } 2 \beta, 6 \alpha \text {-diol }\end{array}$ & Santolina neapolitana & dark-blue \\
\hline 9 & $\begin{array}{l}\text { 2-acetoxy, } 4 \beta, 5 \alpha \text {-epoxy- } 7 \alpha \mathrm{H} \text { - } \\
\text { germacr-1(10)E-ene- } 6 \beta \text {-ol }\end{array}$ & & \\
\hline 10 & $\begin{array}{c}\text { 7aH-germacra-1(10)E,4(15)- } \\
\text { diene- } 2 \beta, 5 \alpha, 6 \beta \text {-triol }\end{array}$ & & mauve \\
\hline 11 & 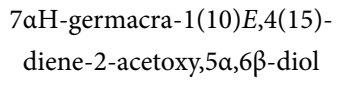 & & \\
\hline 12 & 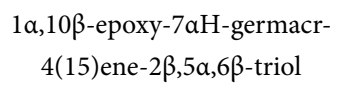 & & \\
\hline $\begin{array}{l}13 \\
14\end{array}$ & $\begin{array}{l}\text { hymenoratin B } \\
\text { hymenovin }\end{array}$ & Helenium hoopesii & orange \\
\hline 15 & $\begin{array}{l}\text { hymenoratin B 2-O- } \beta \text {-D- } \\
\text { (6'-O-acetyl)-glucopyranoside }\end{array}$ & & yellow \\
\hline 16 & floribundin & & lack of colour \\
\hline 17 & lemmonin A & & cherry-red \\
\hline 18 & 2a-tigloyloxydugaldiolide & & \\
\hline 19 & neohymenoratin & & \\
\hline 20 & hymenoratin & & \\
\hline 21 & acetylhymenograndin & & gray \\
\hline
\end{tabular}

\section{Results}

\section{Germacranolides}

The characteristic colour of the spots after spraying with the anisaldehyde reagent of the separated compounds from the aerial parts of Stizolophus balsamita [5], Centaurea bella [3,6], Zoegea baldschuanica [4], Centaurea crocodylium and Centaurea lusitanica [6] can be ascribed to the presence or lack of several substituents at C8 (Fig. 2). Two germacranolides: stizolin (Fig. 1a) and stizolicin (Fig. 1b) of Stizolophus balsamita exhibit, mauve spots on chromatograms, apparently due to the very substituents. It is worth mentioning, that cebellin M (Fig. 1c) - the only one germacranolide among 25 guaianolides found in Centaurea bella, with $\mathrm{OH}$ group in $\mathrm{C} 8$ position, exhibits mauve spots as stizolin (Fig. 1a, Fig. 2a) on chromatograms. It can be inferred from the TLC results of 9a-hydroxyparthenolide (Fig. 1d, Fig. 2b), the germacranolide 


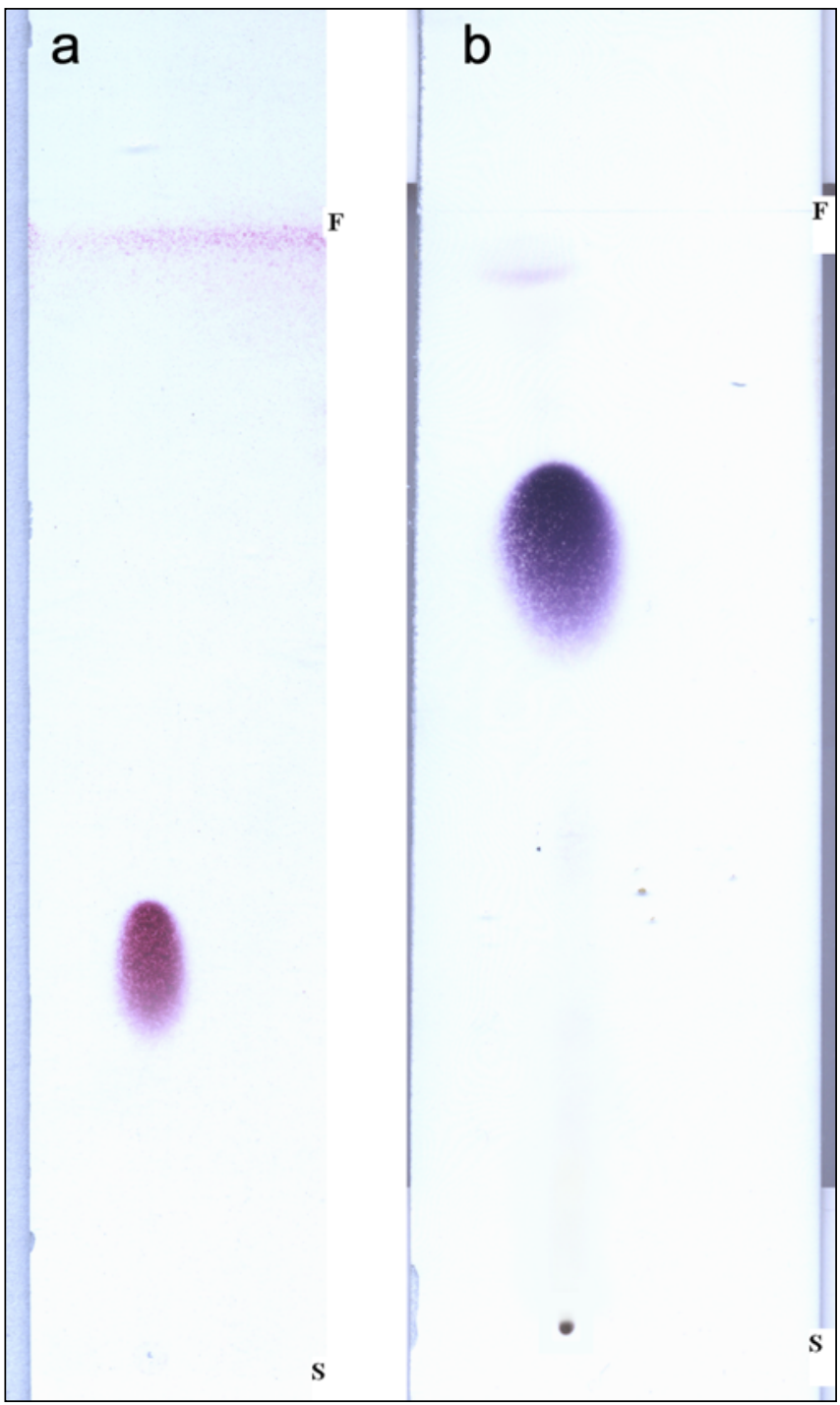

Fig. 2 Chromatogram of 8a-hydroxyparthenolide (stizolin). a Mobile phase: $\mathrm{CH}_{2} \mathrm{Cl}_{2}-\mathrm{CO}\left(\mathrm{CH}_{3}\right)_{2} 3: 1$ and $9 \boldsymbol{\alpha}$ - hydroxyparthenolide. $\mathbf{b}$ Mobile phase: $\mathrm{CH}_{2} \mathrm{Cl}_{2}-\mathrm{CO}\left(\mathrm{CH}_{3}\right)_{2}$ 5:1. Adsorbent: silica gel; reagent: anisaldehyde. $\mathrm{S}$ - start; F - finish.

isolated from Zoegea baldschuanica, devoid of the substituent at $\mathrm{C} 8$, which makes them change the colour of the spots into violet (Fig. 2).

The sesquiterpene lactones in Centaurea crocodylium - salonitenolide (Fig. 1e) and its ester derivative - cnicin (Fig. 1f), have a different structure in comparison to germacranolides from Stizolophus balsamita (Fig. 1a,b). Both possess a characteristic methylhydroxy group at $\mathrm{C} 4$, a substituent at $\mathrm{C} 8$, and change their colour into red-brown on the chromatograms. Non 4,5-epoxy, with $\mathrm{OH}$ at $\mathrm{C}$, derivative of 9a-hydroxyparthenolide (Fig. 1d) - stenophyllolide (Fig. 1g), isolated from Centaurea lusitanica shows black-blue colour of spots on the chromatogram.

\section{Biosynthesis of cnicin during the drying of Centaurea crocodylium herb}

While an attempt was being made to obtain compounds of $C$. crocodylium by column chromatography [silica gel, $\mathrm{CH}_{2} \mathrm{Cl}_{2}-\mathrm{CO}\left(\mathrm{CH}_{3}\right)_{2} 8: 1$ ], from the extract from the fresh herb on large quantity $(665 \mathrm{mg})$, salonitenolide (Fig. 1e) was isolated. Another compound, also in large quantity $(845 \mathrm{mg})$, was obtained [silica gel, $\mathrm{CH}_{2} \mathrm{Cl}_{2}-\mathrm{CO}\left(\mathrm{CH}_{3}\right)_{2} 4: 1$ ] from the dry herb of the plant. To our astonishment, rather than salonitenolide
(Fig. 1e), it turned out to be its ester derivative: cnicin (Fig. 1f). It can be stated, thus, that at the time of drying, the ester had been connected to the hydroxyl group at C8 of e on Fig. 1. It is also worth noting that with the methods used so far in this work, the attempts to isolate either cnicin (Fig. 1f) from the fresh herb, or salonitenolide (Fig. 1e) from the dried herb have been unsuccessful.

\section{Germacranes}

Two out of the five germacranes of Santolina neapolitana [7], with the 4,5 epoxide and a substituent at C2 (Fig. 1i) exhibit dark-blue colour of their spots on the chromatograms (Fig. 3a,c). The spots of compounds $\mathbf{j}, \mathbf{k}, \mathbf{l}$ on Fig. 1 have a different, namely mauve, colour (Fig. 3b,d,e). They lack of the 4,5-epoxide ring and are characterised by the presence of the $\mathrm{OH}$ group at $\mathrm{C} 5$ and the $=\mathrm{CH}_{2}$ substituent at $\mathrm{C} 4$. The 1,10 epoxide of $\mathbf{l}$ on Fig. 1 has no influence on the colour of the spot.

\section{Seco-pseudoguaianolides}

Another type of sesquiterpene lactones occurs in the herb of Helenium hoopesii [8], with seco-pseudoguaianolides (Fig. $1 \mathrm{~m}-\mathrm{p})$ as the dominant feature. Hymenovin - mixture of C3 and/or C4 diastereoisomers (Fig. 1m) and hymenoratin B (Fig. $1 \mathrm{n})$ with pyran skeleton with at least one $\mathrm{OH}$ group at $\mathrm{C} 2$ or $\mathrm{C} 3$ and C4 exhibited orange colour on the chromatograms. Hymenoratin B 2-O- $\beta$-D-(6'-O-acetyl)-glucopyranoside (Fig. $10)$, on the other hand, with a pyran ring and blocked hydroxyl

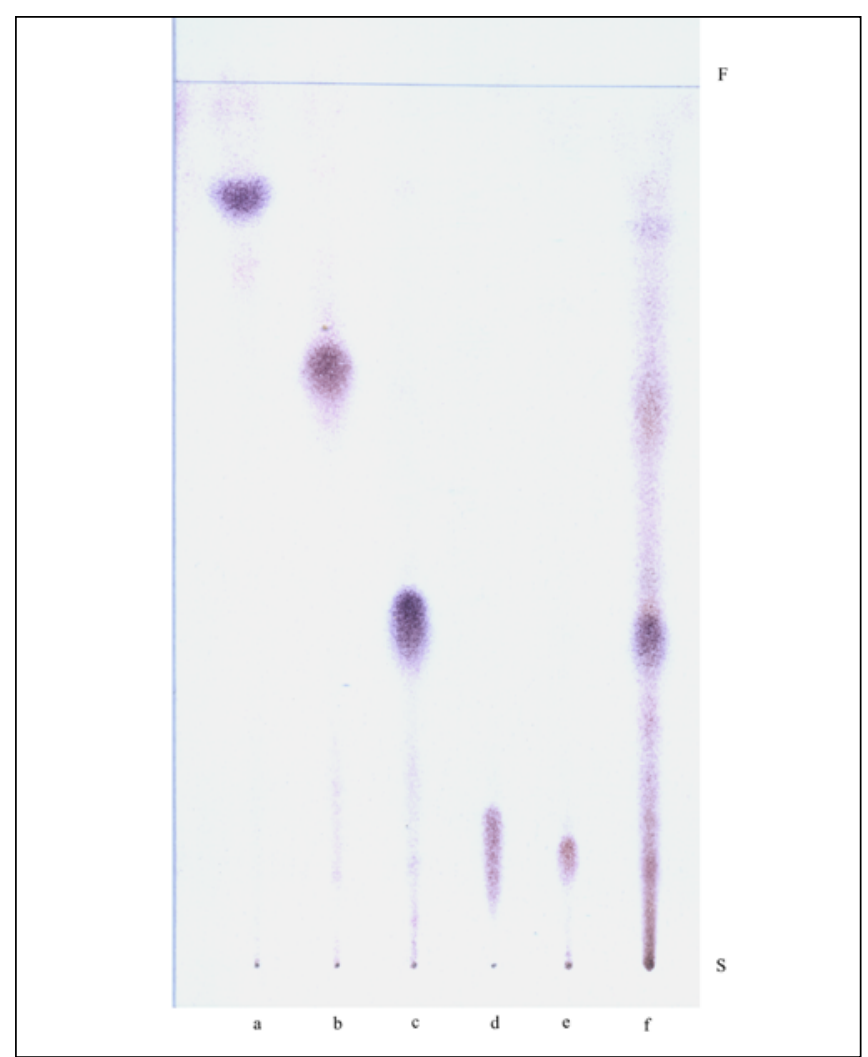

Fig. 3 TLC of germacranes of Santolina neapolitana herb. a 2 -acetoxy, $4 \beta, 5 \alpha$-epoxy-7 $\alpha \mathrm{H}$-germacr-1(10)E-ene- $6 \beta$-ol; b $7 \alpha \mathrm{H}$ germacra-1(10)E,4(15)-diene-2-acetoxy, $5 \alpha, 6 \beta$-diol; c $4 \beta, 5 \alpha$-epoxy$7 \alpha \mathrm{H}$-germacr-1(10)E-ene-2 $\beta, 6 \beta$-diol; $\mathbf{d} 7 \alpha \mathrm{H}$ - germacra- $1(10)$ $E, 4(15)$-diene- $2 \beta, 5 \alpha, 6 \beta$-triol; e $1 \alpha, 10 \beta$-epoxy- $7 \alpha \mathrm{H}$-germacr-4(15) ene- $2 \beta, 5 \alpha, 6 \beta$-triol. $f$ The extract from the herb of Santolina neapolitana. Adsorbent: silica gel; mobile phase: $\mathrm{CHCl}_{3}$ - EtOAc 6:1; reagent: anisaldehyde. S - start; F - finish. 
groups at C2 and C4, changes its colour to yellow on the chromatograms, while floribundin (Fig. 1p), without a substituent at these places, is invisible in the anisaldehyde reagent (but fast crystallizes as white, spectrally clear needles). This compound was presented in this paper for the first time as one of compounds isolated from $H$. hoopesii.

\section{Guaianolides and pseudoguaianolides}

The other compounds of this plant: guaianolides (Fig. 1r,s) and pseudoguaianolides (Fig. 1t,u) with a five-part ring exhibited cherry-red colour. The fading of the cherry-red colour can be observed in acetylhymenograndin (Fig. 1v). Three acetyl groups in this compound are responsible for the grey colour of the spot.

\section{Conclusions}

Sesquiterpenoids constitute an important group of natural compounds occurring in species of family Asteraceae. By means of the simple TLC method, it is possible to estimate several details of the structure within guaianolides, germacranolides, pseudoguaianolides, seco-pseudoguaianolides and germacranes.

The simple thin layer chromatography may surely rank among methods of comparative analysis of natural compounds. It is often easier to differentiate and classify species based on TLC than through the traditional botanical analysis. One might assume that with high probability. Zoegea species will biosynthesize "violet" germacranolides with substituent at C9, and that Stizolophus species will biosynthesize "mauve" germacranolides with substituents at C8, and some Centaurea species will biosynthesize "brown-red" ones, with the characteristic $\mathrm{CH}_{2} \mathrm{OH}$ group at $\mathrm{C} 4$.

\section{References}

1. Saroglou V, Karioti A, Rancic A, Dimas K, Koukoulitsa C, Zervou M, et al. Sesquiterpene lactones from Anthemis melanolepis and their antibacterial and cytotoxic activities. Prediction of their pharmacokinetic profile. J Nat Prod. 2010;73(2):242-246. doi:10.1021/np9004129.

2. Nowak G. Dünnschichtchromatographie von guajanolides des unterstammes Centaureinae. J Chromatogr. 1990;505:417-423.

3. Nowak G. Chromatography of twentysix sesquiterpene lactones from Centaurea bella. Chromatographia. 1993;35(56):325-328. doi:10.1007/BF02277519.

4. Buděšínský M, Šaman D, Nowak G, Drożdż B, Holub M. 9a-hydroxyparthenolide from Zoegea baldschuanica C. Winkl. and its absolute configuration. Collect Czech Chem Commun. 1984;49(3):637-641. doi:10.1135/cccc19840637.

5. Nowak G, Drożdż B, Buděšínský M, Holub M. Sesquiterpene lactones XXXVII. Germacranolides in the genus Stizolophus Cass. Acta Soc Bot Pol. 1989;58(2):247-251.

6. Buděšínský M, Nowak G, Rychlewska U, Hodgson DJ, Šman D, Daniewski WM, et al. Structure of sesquiterpenic lactones of some species of subtribe Centaureinae Dumort. Collect Czech Chem Commun. 1994;59(5):11751202. doi:10.1135/cccc19941175.

7. Kisiel W, Dawid-Pać R, Grabarczyk H, Nowak G. Germacrane derivatives from Santolina pinnata subsp. neapolitana. Z Naturforsch C J Biosci. 2003;58(11-12):793-796.

8. Urbańska M, Nowak G, Kisiel W. Further sesquiterpene lactones from Dugaldia hoopesii. Pol J Chem. 2004;78:169-171. 